\title{
$\begin{array}{ll}\text { Research Square } & \begin{array}{l}\text { Preprints are preliminary reports that have not undergone peer review. } \\ \text { They should not be considered conclusive, used to inform clinical practice, } \\ \text { or referenced by the media as validated information. }\end{array}\end{array}$
}

\section{The Expression of miR-513c and miR-3163 was Downregulated in Tumor Tissues Compared with Margin Tissues of Patients With Breast Cancer}

\author{
Soheila Delgir \\ Tabriz University of Medical Sciences Faculty of Medicine \\ Khandan Ilkhani \\ Tabriz University of Medical Sciences Faculty of Medicine \\ Asma Safi \\ Tabriz University of Medical Sciences Faculty of Medicine \\ Farhad Seif \\ Academic Center for Education Culture and Research \\ Milad Bastami \\ Tabriz University of Medical Sciences \\ Mohammad-Reza Alivand ( $\nabla$ mohammadreza_alivand@yahoo.com ) \\ Tabriz University of Medical Sciences Faculty of Medicine https://orcid.org/0000-0002-5847-3594 \\ Milad Bastami \\ Tabriz University of Medical Sciences
}

\section{Research article}

Keywords: Breast cancer, Glutamine metabolism, Glutaminase, MicroRNA, miR-513c miR-3163

Posted Date: May 29th, 2020

DOI: https://doi.org/10.21203/rs.3.rs-28926/v1

License: () This work is licensed under a Creative Commons Attribution 4.0 International License. Read Full License 


\section{Abstract}

Background Breast cancer (BC) is the most common invasive cancer with different subtypes that its metabolism is unique compared with normal cells. Glutamine is considered a critical nutrition for tumor cell growth and therefore, targeting glutamine metabolism, especially Glutaminase, which catalyzed the conversion of glutamine to glutamate can be beneficial to design anti-cancer agents. Recently, evidence has shown that miRNAs with short length and single strand properties play a significant role in regulating the genes related to glutamine metabolism and may control the development of cancer.

Methods Since, in-silico analysis confirmed that miR-513c and miR-3163 might be involved in glutamine metabolism, the expression level of these two miRNAs was evaluated in eighty BC tissues and margin tissues. The data were analyzed to evaluate the correlation between expression level of these miRNAs and patient's characteristics such as abortion history, family history, and age. Furthermore, in-silico analysis was applied to predict the potential biological processes and molecular pathways of miR-513c and miR-3163 based on its gene targets.

Results In-silico studies revealed the top categories of biological processes and pathways that play a critical role in cancer development were target genes for miR-513c and miR-3163. The current study showed that miR-513c ( $P$-value $=0.02062$ and fold change $=-2.3801)$ and miR-3163 (P-value $=0.02034$ and fold change $=-2.3792)$ were downregulated in tumor tissues compared to margin tissues. Furthermore, the subgroup studies did not show any substantial relationship between expression levels of these two miRNAs and factors such as age, family history cancer, and abortion.

Conclusion Based on our data, miR-513c and miR-3163 may be offered as a potential diagnosis and therapeutic targets for patients with BC.

\section{Background}

Breast cancer (BC) is a major health problem that causes cancer-related mortality in women worldwide [1, 2]. Various subtypes of $\mathrm{BC}$ and their heterogeneity make some problems in early detection of $\mathrm{BC}$ [3]. It is demonstrated that metabolism shifting and some related molecular changes in different types and subtypes of cancers are common and necessary that it can occur in various biomolecules such as enzymes, substrate and products in this pathway. Therefore, they are used as prognostic and diagnostic markers and also, some targeted therapeutic aims [4]. Recently, various pieces of evidence showed that miRNAs as regulators of related enzyme levels play crucial roles in cancer metabolism and are new strategies to manage cancers [5].

Metabolic reprogramming is a unique event in cancer cell development [6], which is utilized to supply the bioenergetic and biosynthetic demands for accelerating growth and proliferation of cancer cells [7]. Glutamine is one of the pivotal amino acids in blood circulation to apply in this pathway and blocking it can suppress the cell proliferation [8]. In glutamine metabolism, Glutaminase (GLS) as a critical and rate-limiting step catalyzes the formation of glutamate from glutamine and accordingly, its expression is associated with tumor malignancy development [9]. Therefore, Glutaminase as a therapeutic strategy in cancer can be regulated by some oncogenes and tumor suppressors [10]. Recently, the valuable studies demonstrated that some emerged microRNAs (miRNAs) can efficiently control glutamine metabolism by GLS targeting, which can provide an opportunity for regulating cancer development [11].

MiRNAs are a class of small non-coding RNAs with 18-25 nucleotides in length, which post-transcriptionally are involved in the regulation of gene expression by degrading targeted mRNAs and/or inhibiting their translation [12]. Recently, the dysregulation of miRNAs have been demonstrated in multiple cancer-related processes, including carcinogenesis, migration, apoptosis, invasion, differentiation, chemoresistance, etc. [13]. Therefore, miRNAs are potential biomarkers for cancer prognosis and diagnosis, thereby providing novel therapeutic opportunities for clinical application [14]. In this regard, bioinformatics analysis indicated that some potent miRNAs such asmiR-513c and miR-3163 can target GLS. 
Regarding further experimental studies, mir-513c is a tumor suppressor in multiple cancers such as hepatocellular carcinoma [15], prostate cancer [16], glioma [17], neuroblastoma [18], and miR-3163 play vital roles in retinoblastoma cancer stem cell (RCSCs) [19] and non-small cell lung cancer cell (NSCLC) cancers [20]. In this study, the expression levels of both miR-513c and miR-3163 as tumor suppressors were evaluated in the patients with BC using in-silico analysis.

\section{Methods}

\subsection{Selection of miRNAs}

To select the most prominent enzyme in glutamine metabolism of tumor cells, the signaling pathways related to glutamine metabolism was examined. Furthermore, the articles reporting the genes involved in Glutamine metabolism were reviewed. Consequently, GLS was selected by using miRTarBase 7.0 [19], Target Scan Human 7.2 databases; then miRNAs which target GLS were searched, recent studies were reviewed for confirmation of these miRNAs. Among numerous miRNAs, miR$513 \mathrm{c}$ and miR-3163 were selected.

\subsection{Clinical specimens}

Firstly, BC tissues and matched margin tissues were obtained from $80 \mathrm{BC}$ patients undergoing surgery at the Noor Nejat Hospital of Tabriz. Written informed consent was obtained from all the participants after enough explanation of the study, and the study was confirmed by ethic committee (Ethic code: IR.TBZMED.REC.1398.025). Patients did not receive chemotherapy or radiotherapy before surgery, and the clinical pathological features of the tissues were diagnosed by pathologists. The specimens were obtained after surgical resection, immediately frozen, and stored at $-80^{\circ} \mathrm{C}$. Clinical pathological features have been shown in (Table 1).

Table 1

Basis characteristics of the patients with breast cancer.

\begin{tabular}{|c|c|}
\hline Parameter & Number (percentage) \\
\hline \multirow[t]{3}{*}{ Tumor grade } & Grade $3=5 \%$ \\
\hline & Grade $2=87.5 \%$ \\
\hline & Grade $1=7.5 \%$ \\
\hline \multirow[t]{2}{*}{ Lymph node } & Yes $=87.5 \%$ \\
\hline & $\mathrm{No}=12.5 \%$ \\
\hline \multirow[t]{3}{*}{ Family Cancer History } & Yes $=47.5 \%$ \\
\hline & $\mathrm{No}=41.3 \%$ \\
\hline & Unknown = $11.2 \%$ \\
\hline \multirow[t]{3}{*}{ Abortion History } & Yes $=36.2 \%$ \\
\hline & No $=51.3 \%$ \\
\hline & Unknown = $12.5 \%$ \\
\hline \multirow[t]{3}{*}{ Age } & $=<5038.8 \%$ \\
\hline & $>5040 \%$ \\
\hline & Unknown = 21.2\% \\
\hline
\end{tabular}

\subsection{Total RNA Extraction}


For extraction of total RNA, the tissue samples were homogenized with liquid nitrogen and their RNA were extracted through Trizol reagent (Geneall). Then, the quality and quantity of extracted RNAs were assessed by using Nano Drop spectrometer (Thermo Scientific, USA). After extraction, the obtained RNAs were eluted in $50 \mu \mathrm{L}$ of RNase-free water and stored at $-80^{\circ} \mathrm{C}$.

\subsection{CDNA synthesis and Real-time PCR}

In this study, cDNA of the miR-3163, miR-513c and RNU6 were synthesized by using reverse transcriptase enzyme (Thermo Fisher, USA), dNTP (Sinaclon, Iran), and their unique stem-loop-primers. For this purpose, three specific stem-loop primers were designed for miR-3163, miR-513c, and also RNU6 (for normalization) were employed and the conditions of PCR machines were $30 \mathrm{~min}$ at $16{ }^{\circ} \mathrm{C}, 30 \mathrm{~min}$ at $42^{\circ} \mathrm{C}$ and $5 \mathrm{~min}$ at $75^{\circ} \mathrm{C}$ (Table 2). For conducting Real-time PCR reaction, the SYBR Green master mix (Amplicon, Denmark), miR-3163, miR-513c specific primers and dNTP were used (Table 2). These reactions were performed by MIC PCR bimolecular system in two steps as follows: for miR-513c: 10 min at $94{ }^{\circ} \mathrm{C}, 40 \mathrm{cycles}$ of $15 \mathrm{sec}$ at $94{ }^{\circ} \mathrm{C}$ and $30 \mathrm{sec}$ at $58^{\circ} \mathrm{C}$. For miR-3163: $10 \mathrm{~min}$ at $94{ }^{\circ} \mathrm{C}, 40$ cycles of $15 \mathrm{sec}$ at $94{ }^{\circ} \mathrm{C}$ and $20 \mathrm{~s}$ at $57^{\circ} \mathrm{C}$. Then, for RNU6 amplification :10 min at $94^{\circ} \mathrm{C}, 40$ cycles in $15 \mathrm{sec}$ at $94^{\circ} \mathrm{C}$ and $20 \mathrm{~s}$ at $56^{\circ} \mathrm{C}$. The results were shown by mic-PCR v1.4.0 software. The sequences of the primers are shown in Table 2.

Table 2

cDNA synthesis specific stem-loop primers and Real-time PCR primer sequences.

\begin{tabular}{|c|c|c|c|}
\hline & $\begin{array}{l}\text { Noncoding- } \\
\text { RNAs and } \\
\text { their } \\
\text { accession } \\
\text { numbers }\end{array}$ & Sequences & \\
\hline \multirow[t]{3}{*}{$\begin{array}{l}\text { cDNA } \\
\text { synthesis } \\
\text { reaction }\end{array}$} & $\begin{array}{l}\text { MiR-3163-5p } \\
\text { NIMAT } \\
0015037\end{array}$ & $\begin{array}{l}\text { MiR- } \\
\text { 3163(STL) }\end{array}$ & $\begin{array}{l}\text { 5'- } \\
\text { GTCGTATCCAGTGCAGGGTCCGAGGTATTCGCACTGGATACGACGTCTTAC- } \\
3^{\prime}\end{array}$ \\
\hline & $\begin{array}{l}\text { Mir-513c-5p } \\
\text { NIMAT } \\
0022728\end{array}$ & $\begin{array}{l}\text { Mir- } \\
513 c(S T L)\end{array}$ & $\begin{array}{l}\text { 5'-GTCGTATCCAGTGCAGGGTCCGAGGTATTCGCACTGGATACGACATAAAC- } \\
3^{\prime}\end{array}$ \\
\hline & $\begin{array}{l}\text { RNU6 } \\
\text { NR_003027.2 }\end{array}$ & U6 (STL) & $\begin{array}{l}\text { 5'- } \\
\text { GTCGTATCCAGTGCAGGGTCCGAGGTATTCGCACTGGATACGACAAAAATAT- } \\
3^{\prime}\end{array}$ \\
\hline \multirow[t]{5}{*}{$\begin{array}{l}\text { Real time } \\
\text { PCR } \\
\text { reaction }\end{array}$} & $\begin{array}{l}\text { MiR-3163-5p } \\
\text { NIMAT } \\
0015037\end{array}$ & $\begin{array}{l}\text { Mir- } \\
3163(\mathrm{~F})\end{array}$ & 5'-AGGGTATAAAATGAGGGCAGTAAGAC-3' \\
\hline & $\begin{array}{l}\text { Mir-513c-5p } \\
\text { NIMAT } \\
0022728\end{array}$ & $\begin{array}{l}\text { Mir- } \\
513 c(F)\end{array}$ & 5'-GGGTTCTCAAGGAGGTGTCG-3' \\
\hline & $\begin{array}{l}\text { MiR-3163\& } \\
\text { Mir-513c }\end{array}$ & $\begin{array}{l}\text { Common } \\
\text { (R) }\end{array}$ & 5'-GTGCAGGGTCCGAGGT-3' \\
\hline & RNU6 & U6 (F) & 5'-GCTTCGGCAGCACATATACTAAAAT-3' \\
\hline & NR_003027.2 & U6 (R) & 5'-CGCTTCACGAATTTGCGTGTCAT-3' \\
\hline
\end{tabular}

\subsection{In-silico analysis}

In-silico analysis was performed to evaluate biological processes that are targeted by miR-513c-5p and miR-3163. The experimentally confirmed targets of miR-513c-5p and miR-3163 were obtained from the miRTarBase 6.0 database 
(http://mirtarbase.mbc.nctu.edu.tw/php/index.php) and exposed to overrepresentation enrichment analysis (ORA) based on the Gene Ontology (GO) and the Kyoto Encyclopedia of Genes and Genomes pathways using the Web Gestalt (http://www.webgestalt.org/option.php) web server. In both analyses, the reference gene list and the multiple test adjustment method were set to "genome_protein_coding" and Benjamini-Hochberg, respectively. In the GO analysis, the 10 top important categories were selected. Other parameters were set as defaults.

\subsection{Statistical analysis}

All of the experiments were performed at least two times. Shapiro-Wilk test was checked whether data are normally distributed or not. Paired t-test and delta-CTs are used for comparison the gene expressions between tumor tissues and margins. Two sample t-test and logarithm2 of fold, applied to compare expression alterations of genes in tumors relative to margins tissue across subsets of study samples. All statistical analyses were conducted using R software version 0.5 . 1.Finally, $P<0.05$ was considered statistically significant.

\section{Results}

Based on miRTarBase, miRDB, and Target Scan Human 7.2, miR- related databases, miR-513c and miR-3163 were selected as potential miRNAs targeting GLS. To determine the roles of miR-513c and miR-3163 in human breast cancer, we compared the expressions of both miRNAs in 80 of human breast cancer tissues and their margin tissues were obtained from patients undergoing surgery at the Noor Nejat Hospital of Tabriz.

\subsection{MiR-513c and miR-3163 are downregulated in breast cancer tissues}

\subsubsection{MiR-513c}

The results of paired T-test show that expression level of miR-513c was relatively downregulated in human breast cancer tissues compared to non-tumor adjacent tissues ( $P$-value $=0.02062)$ and (fold change $=-2.3801)$.

\subsubsection{MiR-3163}

The results of paired t-test reveal that expression level of miR-3163 was relatively downregulated in human breast cancer tissues compared to non-tumor adjacent tissues (P-value $=0.02034)$ and (fold change=-2.3792).

\subsection{Subgroups analysis}

To show the relationship between the expression of miR-513c and miR-3163 with factors such as age, family history cancer, and abortion in breast cancer subgroups, sample t-test of logarithm2 of fold changes were employed.

\subsubsection{MiR-513c}

We did not find any significant changes in the expression of miR-513c in age subgroups of $\leq 50$ years and $>50$ years ( $P$ value $=0.6758$ ) and (fold change $=-0.42103$ ) (Fig. 1 left). Additionally, our analysis has been proved, there is no significant relationship between the expression of miR-513c with abortion (P-value $=0.7713)$ and (fold change $=0.29275)(F i g u r e .1$ middle) and cancer family history subgroups ( $P$-value $=0.0525)$ and (fold change $=-1.9859)$ (Figure.1 right).

\subsubsection{MiR-3163}

Based on results of paired sample t-test, there is no markedly changes in the expression level of miR-3163in subgroups cancer family history $(P$-value $=0.1208)$, (fold change $=-1.5756)$ (Figure.2 left). Additionally, our data showed that there is 
no significant relationship between the expression of miR-3163 with abortion history (P-value $=0.5634)$, (fold change $=$ 0.58281 ) (Fig. 2 middle), and age in patients $<=50$ and $<50$ (P-value $=0.3805)$, (fold change = 0.8859) (Fig. 2 right).

\subsection{In-silico analysis}

A total of 98 and 333 experimentally proved target genes for miR-513c and miR-3163 were extracted from the miRTarBase database, respectively. The miRNA-gene interaction was portrayed by Cytoscape V 3.7.1 (Fig. 3, 4). The ORA showed that significant categories of biological procedures were overrepresented among target gene of miR-513c and miR-3163 $($ Table 3,4$)$. Moreover, pathway analysis revealed top biological enriched-pathways and processes in target gene of miR513c and miR-3163 (Table 5, 6).

Table 3

Pathways that are enriched among target genes of mir-513c.

\begin{tabular}{|lllllll|}
\hline No & ID & Pathway name & O & FDR & E & P-value \\
\hline 1 & hsa05222 & Small cell lung cancer & 92 & 1 & 0.34163 & 0.0046026 \\
\hline 2 & hsa00130 & Ubiquinone and other terpenoid-quinone biosynthesis & 11 & 1 & 0.040847 & 0.040124 \\
\hline 3 & hsa05200 & Pathways in cancer & 524 & 1 & 1.9458 & 0.041062 \\
\hline 4 & hsa05032 & Morphine addiction & 91 & 1 & 0.33792 & 0.044411 \\
\hline $\begin{array}{l}\text { Abbreviations: E, number of expected genes in each category; O, number of observed target genes in each specific } \\
\text { category. }\end{array}$
\end{tabular}


Pathways that are enriched among target genes of miRNA-3163

\begin{tabular}{|c|c|c|c|c|c|c|c|}
\hline Nos & Gene set & Pathway name & $\mathrm{C}$ & $\mathrm{E}$ & $\mathbf{R}$ & FDR & $\begin{array}{l}\mathrm{P}- \\
\text { value }\end{array}$ \\
\hline 1 & hsa05170 & Human immunodeficiency virus 1 infection & 212 & 3.6155 & 3.3191 & 0.081094 & $\begin{array}{l}2.5 \mathrm{E}- \\
04\end{array}$ \\
\hline 2 & hsa04110 & Cell cycle & 124 & 2.1147 & 3.783 & 0.09676 & $\begin{array}{l}1 \mathrm{E}- \\
03\end{array}$ \\
\hline 3 & hsa04114 & Oocyte meiosis & 124 & 2.1147 & 3.783 & 0.09676 & $\begin{array}{l}1 \mathrm{E}- \\
03\end{array}$ \\
\hline 4 & hsa05202 & Transcriptional misregulation in cancer & 186 & 3.1721 & 3.1525 & 0.09676 & $\begin{array}{l}1 \mathrm{E}- \\
03\end{array}$ \\
\hline 5 & hsa04010 & MAPK signaling pathway & 295 & 5.0309 & 2.584 & 0.09676 & $\begin{array}{l}1.5 \mathrm{E}- \\
03\end{array}$ \\
\hline 6 & hsa05167 & $\begin{array}{l}\text { Kaposi sarcoma-associated herpesvirus } \\
\text { infection }\end{array}$ & 186 & 3.1721 & 2.8373 & 0.2378 & $\begin{array}{l}4.4 \mathrm{E}- \\
03\end{array}$ \\
\hline 7 & hsa04340 & Hedgehog signaling pathway & 47 & 0.80154 & 4.9904 & 0.3802 & $\begin{array}{l}8.2 \mathrm{E}- \\
03\end{array}$ \\
\hline 8 & hsa04310 & Wnt signaling pathway & 146 & 2.4899 & 2.8114 & 0.49589 & $\begin{array}{l}1 \mathrm{E}- \\
02\end{array}$ \\
\hline 9 & hsa05206 & MicroRNAs in cancer & 150 & 2.5581 & 2.7364 & 0.50585 & $\begin{array}{l}1.4 \mathrm{E}- \\
02\end{array}$ \\
\hline 10 & hsa04218 & Cellular senescence & 160 & 2.7286 & 2.5654 & 0.58131 & $\begin{array}{l}2 \mathrm{E}- \\
02\end{array}$ \\
\hline \multicolumn{8}{|c|}{$\begin{array}{l}\text { Abbreviations: } C \text {, the total number of genes in the category; } E \text {, number of expected genes in each category; } R \text {, fold } \\
\text { enrichment. }\end{array}$} \\
\hline aTh & amini-r & erg adjusted $P$-value & & & & & \\
\hline
\end{tabular}


Top ten enriched biological processes among target genes of miR-513c.

\begin{tabular}{|c|c|c|c|c|c|c|c|}
\hline No & GO ID & Biological process & 0 & FDR & E & $\mathbf{R}$ & $\begin{array}{l}P- \\
\text { value }\end{array}$ \\
\hline 1 & GO:0042148 & strand invasion & 5 & 1 & 0.024004 & 83.32 & $\begin{array}{l}2.2 \mathrm{E}- \\
04\end{array}$ \\
\hline 2 & GO:0006612 & protein targeting to membrane & 187 & 1 & 0.89774 & 6.6834 & $\begin{array}{l}2.7 \mathrm{E}- \\
04\end{array}$ \\
\hline 3 & G0:0045047 & protein targeting to $E R$ & 107 & 1 & 0.51368 & 7.7869 & $\begin{array}{l}1.7 \mathrm{E}- \\
03\end{array}$ \\
\hline 4 & GO:0072599 & $\begin{array}{l}\text { establishment of protein localization to } \\
\text { endoplasmic reticulum }\end{array}$ & 111 & 1 & 0.53289 & 7.5063 & $\begin{array}{l}1.9 \mathrm{E}- \\
03\end{array}$ \\
\hline 5 & GO:0008340 & determination of adult lifespan & 17 & 1 & 0.081613 & 24.506 & $\begin{array}{l}2.9- \\
\text { E3 }\end{array}$ \\
\hline 6 & GO:0006605 & protein targeting & 412 & 1 & 1.9779 & 3.5391 & $\begin{array}{l}3.6 \mathrm{E}- \\
03\end{array}$ \\
\hline 7 & G0:0090150 & $\begin{array}{l}\text { establishment of protein localization to } \\
\text { membrane }\end{array}$ & 313 & 1 & 1.5026 & 3.993 & $\begin{array}{l}3.9- \\
03\end{array}$ \\
\hline 8 & GO:0070972 & protein localization to endoplasmic reticulum & 137 & 1 & 0.65771 & 6.0818 & $\begin{array}{l}4.2 \mathrm{E}- \\
03\end{array}$ \\
\hline 9 & GO:0031297 & replication fork processing & 95 & 1 & 0.15362 & 13.019 & $\begin{array}{l}1 \mathrm{E}- \\
02\end{array}$ \\
\hline 10 & GO:0006614 & $\begin{array}{l}\text { SRP-dependent co-translational protein targeting } \\
\text { to membrane }\end{array}$ & 95 & 1 & 0.45607 & 6.5779 & $\begin{array}{l}1 \mathrm{E}- \\
02\end{array}$ \\
\hline \multicolumn{8}{|c|}{$\begin{array}{l}\text { Abbreviations: } C \text {, the total number of genes in the category; } E \text {, number of expected genes in the category; GO, Gene } \\
\text { Ontology; R, fold enrichment; } \mathrm{O} \text {, number of observed target genes in each specific category. }\end{array}$} \\
\hline
\end{tabular}


Table 6

Top ten enriched biological processes among target genes of miR-3163

\begin{tabular}{|c|c|c|c|c|c|c|c|}
\hline No & Gene set & Biological pathways & C & $\mathbf{E}$ & $\mathbf{R}$ & FDR & $\begin{array}{l}\mathrm{P}- \\
\text { value }\end{array}$ \\
\hline 1 & GO:0045934 & $\begin{array}{l}\text { negative regulation of nucleobase-containing } \\
\text { compound metabolic process }\end{array}$ & 1418 & 22.805 & 1.9732 & 0.04352 & $\begin{array}{l}8 \mathrm{E}- \\
06\end{array}$ \\
\hline 2 & GO:0033554 & cellular response to stress & 1867 & 30.026 & 1.7984 & 0.04352 & $\begin{array}{l}1 \mathrm{E}- \\
05\end{array}$ \\
\hline 3 & G0:0010629 & negative regulation of gene expression & 1733 & 27.871 & 1.8299 & 0.04352 & $\begin{array}{l}1 \mathrm{E}- \\
05\end{array}$ \\
\hline 4 & GO:1903311 & regulation of mRNA metabolic process & 266 & 4.278 & 3.5063 & 0.06326 & $\begin{array}{l}3 \mathrm{E}- \\
05\end{array}$ \\
\hline 5 & GO:0045935 & $\begin{array}{l}\text { positive regulation of nucleobase-containing } \\
\text { compound metabolic process }\end{array}$ & 1847 & 29.705 & 1.7169 & 0.12664 & $\begin{array}{l}8 \mathrm{E}- \\
05\end{array}$ \\
\hline 6 & GO:0000278 & mitotic cell cycle & 927 & 14.909 & 2.0793 & 0.12664 & $\begin{array}{l}9 \mathrm{E}- \\
05\end{array}$ \\
\hline 7 & GO:0051253 & negative regulation of RNA metabolic process & 1295 & 20.827 & 1.8726 & 0.12664 & $\begin{array}{l}1 \mathrm{E}- \\
04\end{array}$ \\
\hline 8 & GO:0000902 & cell morphogenesis & 982 & 15.793 & 2.0262 & 0.12664 & $\begin{array}{l}1 \mathrm{E}- \\
04\end{array}$ \\
\hline 9 & GO:0032989 & cellular component morphogenesis & 1082 & 17.401 & 1.9539 & 0.12664 & $\begin{array}{l}1 \mathrm{E}- \\
04\end{array}$ \\
\hline 10 & GO:2000113 & $\begin{array}{l}\text { negative regulation of cellular macromolecule } \\
\text { biosynthetic process }\end{array}$ & 1359 & 21.856 & 1.8301 & 0.12664 & $\begin{array}{l}1 \mathrm{E}- \\
04\end{array}$ \\
\hline
\end{tabular}

\section{Discussion}

$\mathrm{BC}$ is the most common invasive cancer and the main leading cause of cancer death in women [21]. The exact mechanism of $\mathrm{BC}$, because of its heterogeneity and complexity, is unclear. Therefore, it is required to identify novel diagnostic and prognostic biomarkers. Recently, microRNAs are considered to paly critical roles in the development of BC as critical molecular regulators [22]. Shifting of metabolism pathways is a significant property of breast cancer subtypes. Therefore, studying the metabolism profile can be a valuable approach to control cancer cells [23].

Glutamine is a necessary nutrient required for the growth and survival of a potentially large subset of tumors such as breast cancer [7]. However, the role of glutamine metabolism on proliferation of breast cancer is still unknown. Recently, targeting cancer metabolism, especially inhibition of metabolic enzymes which are pivotal in cancer development, can be a great strategy in developing anti-cancer therapy. Glutaminase (GLS) as a crucial enzyme, which catalyzes the conversion glutamine to glutamate, may be a target in control cancer. Based on evidence, miRNAs play an important role in the regulation of cell metabolism [24]. According to bioinformatics databases, miRNAs such as mir-513c and miR-3163 are involved in glutamine metabolism which have been evaluated in this study.

Based on recent evidences, the downregulation of mir-513c in multiple cancers and tumor suppressor role of miR-513c has been proved. In hepatocellular carcinoma, FLVCR1-AS1 as a IncRNA which its expression is associated with cancer properties such as apoptosis, migration, invasion and proliferation. FLVCR1-AS1 by directly sponging mir-513c leads to upregulate MET in HCC. Therefore, mir-513c through targeting MET prevented proliferation cancer cells [15]. In neuroblastoma, mir-513c is markedly downregulated. Furthermore, mir-513c as a tumor suppressor, plays an important role in regulating glutamine metabolism through targeting GLS [18]. Additionally, in glioblastoma (GBM) miR-513c was 
significantly downregulated. the Wnt/ $\beta$-catenin is a critical pathway signaling in GBM progression [25]. Low-density lipoprotein (LDL) receptor-related protein-6 (LPR6) is a key component of the LRP5/LRP6/Frizzled complex that is involved in activation of Wnt/ $\beta$-catenin. Bioinformatics studies have proved LPR6 is a potential target of mir-513c. Therefore, mir$513 \mathrm{c}$ as a tumor suppressor may inhibit the proliferation of cancer cells in GBM [17].

Since the role of miR-513c-5p has not been fully understand, a bioinformatics analysis was done to shed the light on molecular pathways and biological procedures that are potentially effected by dysregulation of miR-513c-5p. In-silico studies proved that target genes of miR-513c are involved in pathways related to cancer progression. In the present study, miR-513c was relatively downregulated in BC tissues compared with margin tissues. Based on our research, several studies have been carried out on mir-513c but this is the first study that was done on breast cancer cell line and clinical samples. Our findings, similar to previous studies, showed decreased expression of mir-513c. Therefore, it seems mir-513c as a tumor suppressor may be a biomarker for prognosis and diagnosis of patients with breast cancer.

In several studies, the activity and expression of mir-3163 in multiple cancers such as NSCLC and Retinoblastoma (RB) have been evaluated. In NSCLC, mir-3163 as a moderator contributes to Meg3 to suppress and regulate the translation of skp2. However, the mir-3163 expression do not differ in NSCLC compared with normal cells, which suppresses the skp2 translation and reduction of its level in corporation with Meg3 to decrease cell proliferation in NSCLC [20]. Retinoblastoma (RB) is the most common eye malignancy of childhood [26]. Multidrug resistance is a significant problem in the treatment failure in RB [27]. Based on new investigations, ABCG2 as an important contributing agent to multidrug resistance [28] is a potential target of mir-3163. Therefore, upregulation of mir-3163 suppressed ABCG2 expression, which subsequently reduced the multidrug resistance and promotion of apoptosis in RCSC [19].

Meanwhile, because the activity of miR-3163 has not been completely comprehended bioinformatics analysis was performed in cancers to determine the relationship between cancer and miR-3163. This analysis provides an insight into molecular pathways and biological processes that are potentially regulated by target gene of miR-3163. Among multiple significant pathways influence by miR-3163, MAPK signaling pathway, Hedgehog signaling pathway, Wnt signaling pathway are of most important and might obtain a valuable clue for connection between miR-3163 and breast cancer. MAPK signaling pathway is a critical key regulator in cellular functions, like cell differentiation, proliferation, differentiation, survival and apoptosis. The higher MAPK expression in subtypes of BC leads to invasive phenotypes and poor prognosis [29-31]. Hedgehog signaling pathway is another signaling pathways that constitutively dysregulated in BC cells. Also, this pathway plays a critical role in the development of $\mathrm{BC}$ [32]. MiR-3163 is also related to the Wnt signaling that has a significant role in several biological processes. It has been proved that dysregulation of Wnt signaling leads to the progression of $\mathrm{BC}[33]$.

In the present study, our data contrary to previous studies have proved that the expression of mi-3163 was relatively downregulated in BC tissues compared with margin tissues. Recent reports have shown that miR-3163 plays diverse roles in various cancers; nonetheless, further studies are needed to identify the precise role of this microRNA. Based on our data and bioinformatics analysis, it seems that miR-3163 as a tumor suppressor may act as a biomarker in the prediction and diagnosis of patients with BC. Overall, based on our analysis, no significant association was found between miR-513c and miR-3163 expression and variables such as age, cancer family history, abortion.

\section{Conclusion}

Altogether, based on our results, mir-513c and mir-3163 expression are relatively downregulated in breast cancer tissues in comparison to margin tissues. Therefore, mir-513c and mir-3163 may serve as a diagnostic and prognostic marker in patients with breast cancer. Additionally, according to our data, there is not remarkable association between the expression of both miRNAs with factors such as such as age, abortion history, and cancer family history. However, further studies are needed to elucidate to molecular mechanism and validate bioinformatics results.

Page 10/16 


\section{Abbreviations}

BC, Breast Cancer; GLS, Glutaminase; HCC, hepatocellular carcinoma; LPR6, Low-density lipoprotein (LDL) receptor-related protein-6; RB, Retinoblastoma; GBM, Glioblastoma

ABCG2, ATP Binding Cassette Subfamily G Member 2; MEG3, Maternally Expressed 3; RCSCs, Retinoblastoma Cancer Stem Cells; NSCLC, Non-small cell lung cancer.

\section{Declarations}

Ethics approval and consent to participate: This study was approved by the Ethics Committee of Tabriz University of Medical Sciences, Tabriz, Iran with Ethics code IR.TBZMED.REC.025.

Consent for publication: Not Applicable

Availability of data and materials: The data that support the findings of this study are available on request from the corresponding author. The data are not publicly available due to privacy or ethical restrictions.

Competing Interests: The authors declare no conflict of interest.

Funding: This study was supported by Immunology Research Center (grant No. 109/97) of Tabriz University of Medical Sciences, Tabriz, Iran

Author's contribution: Shila Delghir designed the study. Mohammad Reza Alivand and Farhad Seif wrote the first draft of the manuscript. Milad Bastami, Asma Safei, and Khandan Ilkhani gathered the data. Milad Bastami and Mohammad Reza Alivand supervised the study. All authors read and approved the final version of the manuscript.

Acknowledgements: We would like to express our gratitude to personnel of medical genetic lab at dep. of Medical Genetics.

\section{References}

1. Hamam R, et al. microRNA expression profiling on individual breast cancer patients identifies novel panel of circulating microRNA for early detection. Scientific reports. 2016;6:25997.

2. McGuire A, Brown JA, Kerin MJ. Metastatic breast cancer: the potential of miRNA for diagnosis and treatment monitoring. Cancer metastasis reviews. 2015;34(1):145-55.

3. Ng CK, Pemberton HN, Reis-Filho JS. Breast cancer intratumor genetic heterogeneity: causes and implications. Expert Rev Anticancer Ther. 2012;12(8):1021-32.

4. Sheng C, et al. Knockdown of Ran GTPase expression inhibits the proliferation and migration of breast cancer cells. Mol Med Rep. 2018;18(1):157-68.

5. Martinez-Outschoorn UE, et al. Cancer metabolism: a therapeutic perspective. Nature reviews Clinical oncology. 2017;14(1):11.

6. Bacci M, et al. miR-155 drives metabolic reprogramming of ER + breast cancer cells following long-term estrogen deprivation and predicts clinical response to aromatase inhibitors. Cancer research. 2016;76(6):1615-26.

7. Hensley CT, Wasti AT, DeBerardinis RJ. Glutamine and cancer: cell biology, physiology, and clinical opportunities. J Clin Investig. 2013;123(9):3678-84.

8. El Ansari R, et al. Altered glutamine metabolism in breast cancer; subtype dependencies and alternative adaptations. Histopathology. 2018;72(2):183-90.

9. Gross MI, et al. Antitumor activity of the glutaminase inhibitor CB-839 in triple-negative breast cancer. Mol Cancer Ther. 2014;13(4):890-901. 
10. Lukey MJ, et al. The oncogenic transcription factor c-Jun regulates glutaminase expression and sensitizes cells to glutaminase-targeted therapy. Nature communications. 2016;7:11321.

11. Gao P, et al. c-Myc suppression of miR-23a/b enhances mitochondrial glutaminase expression and glutamine metabolism. Nature. 2009;458(7239):762.

12. Iorio MV, et al. MicroRNA gene expression deregulation in human breast cancer. Cancer research. 2005;65(16):706570.

13. Peng $Y$, Croce CM. The role of MicroRNAs in human cancer. Signal transduction targeted therapy. 2016;1:15004.

14. Blenkiron $\mathrm{C}$, et al. MicroRNA expression profiling of human breast cancer identifies new markers of tumor subtype. Genome biology. 2007;8(10):R214.

15. Zhang K, et al. LncRNA FLVCR1-AS1 acts as miR-513c sponge to modulate cancer cell proliferation, migration, and invasion in hepatocellular carcinoma. Journal of cellular biochemistry. 2018;119(7):6045-56.

16. Wang B-D, et al. Identification and functional validation of reciprocal microRNA-mRNA pairings in African American prostate cancer disparities. Clin Cancer Res. 2015;21(21):4970-84.

17. Xu J, Sun T, Hu X. microRNA-513c suppresses the proliferation of human glioblastoma cells by repressing low-density lipoprotein receptor-related protein 6. Mol Med Rep. 2015;12(3):4403-9.

18. Xia H-L, et al. MiR-513c suppresses neuroblastoma cell migration, invasion, and proliferation through direct targeting glutaminase (GLS). Cancer Biomarkers. 2017;20(4):589-96.

19. Jia M, et al. Silencing of ABCG2 by microRNA-3163 inhibits multidrug resistance in retinoblastoma cancer stem cells. J Korean Med Sci. 2016;31(6):836-42.

20. Su L, et al. Skp2 regulates non-small cell lung cancer cell growth by Meg3 and miR-3163. Tumor Biology. 2016;37(3):3925-31.

21. Bahrami A, et al. The prognostic and therapeutic application of microRNAs in breast cancer: Tissue and circulating microRNAs. Journal of cellular physiology. 2018;233(2):774-86.

22. Denis $\mathrm{H}$, et al. MicroRNAs regulate KDM5 histone demethylases in breast cancer cells. Mol BioSyst. 2016;12(2):40413.

23. Dupuy F, et al. PDK1-dependent metabolic reprogramming dictates metastatic potential in breast cancer. Cell Metabol. 2015;22(4):577-89.

24. Chen B, et al. Roles of microRNA on cancer cell metabolism. Journal of translational medicine. 2012;10(1):228.

25. Kim Y, et al. Wnt activation is implicated in glioblastoma radioresistance. Laboratory investigation. 2012;92(3):466.

26. Dimaras H, et al. Retinoblastoma Nature reviews Disease primers. 2015;1:15021.

27. Busch $\mathrm{M}$, et al. Characterization of etoposide-and cisplatin-chemoresistant retinoblastoma cell lines. Oncol Rep. 2018;39(1):160-72.

28. Hendig D, et al. Characterization of the ATP-binding cassette transporter gene expression profile in Y79: a retinoblastoma cell line. Molecular cellular biochemistry. 2009;328(1-2):85-92.

29. Mittal S, et al. Cooperation of Notch and Ras/MAPK signaling pathways in human breast carcinogenesis. Mol Cancer. 2009;8(1):128.

30. Jia Y, et al. KLF4 overcomes tamoxifen resistance by suppressing MAPK signaling pathway and predicts good prognosis in breast cancer. Cellular signalling. 2018;42:165-75.

31. Mirzoeva OK, et al. Basal subtype and MAPK/ERK kinase (MEK)-phosphoinositide 3-kinase feedback signaling determine susceptibility of breast cancer cells to MEK inhibition. Cancer research. 2009;69(2):565-72.

32. Souzaki M, et al. Hedgehog signaling pathway mediates the progression of non-invasive breast cancer to invasive breast cancer. Cancer Sci. 2011;102(2):373-81. 
33. Koval A, Katanaev VL. Dramatic dysbalancing of the Wnt pathway in breast cancers. Scientific reports. 2018;8(1):110.

\section{Figures}
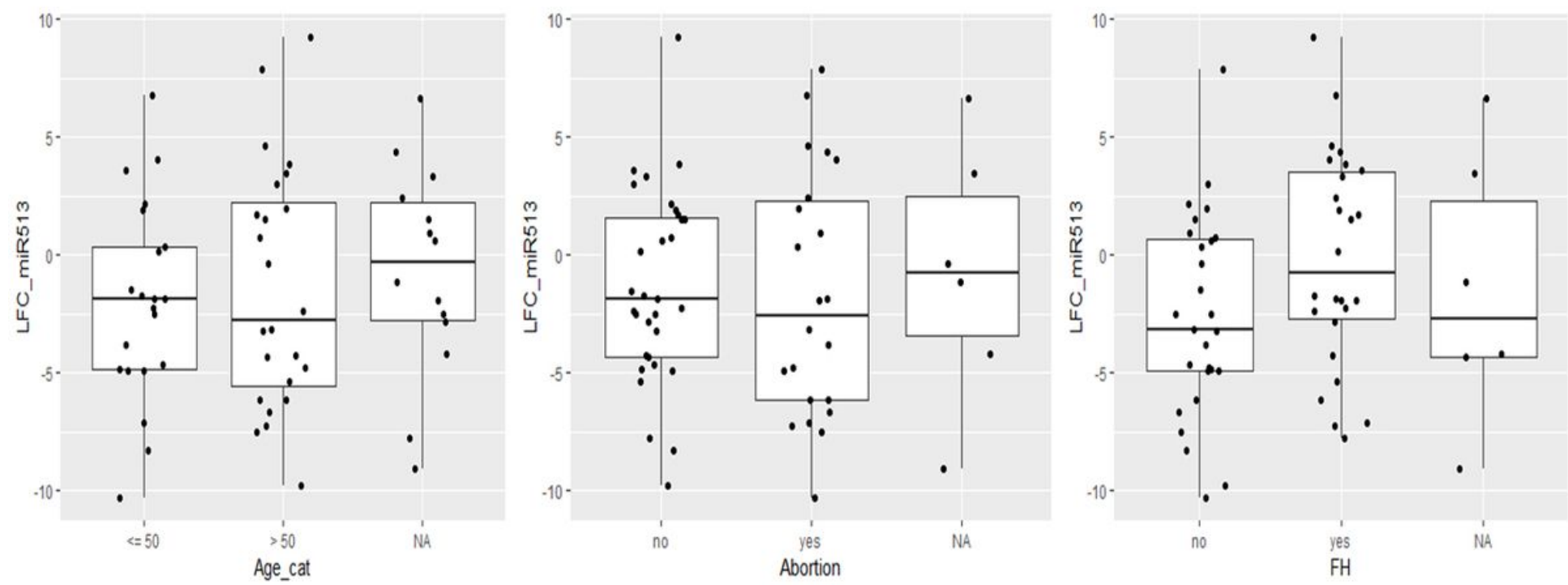

\section{Figure 1}

left. Boxplot of cancer expression level of mir-513c and age, patients $>50(n=31)$, patients $<=50(n=31)$, age unknown for $(n=18)$ cases. (P-value=0.6758). Middle. Boxplot of abortion history and expression level of miR-513c. Patients without abortion history $(n=41)$, patients with abortion history $(n=29)$, unknown abortion history $(n=10)$. (P-value=0.7713) right. Boxplot of cancer expression level of mir-513c and family history. Patients with family history $(n=38)$, patients without family history $(n=33)$, unknown family history $(n=9)$ (P-value=0.0525). 

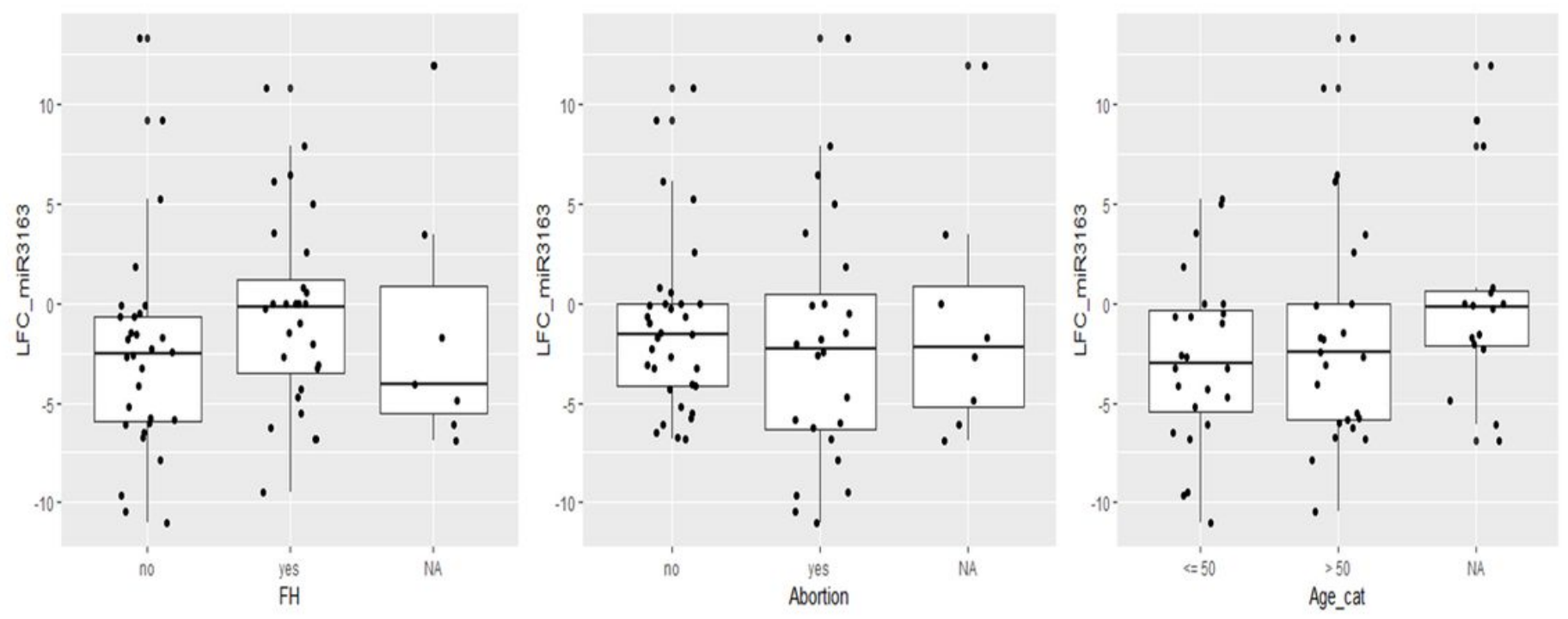

Figure 2

Left. Boxplot of cancer family history and expression level of mir-3163. Patients with family history ( $n=38)$, patients without family history $(n=33)$, unknown family history $(n=9)$. ( $p$-value= 0.1208$)$. Middle. Boxplot of abortion history and expression level of miR-3163. Patient without abortion history $(n=41)$, patients with abortion history $(n=29)$, unknown abortion history $(n=10)$. ( $p$-value= 0.5634). Right. Boxplot of ages and expression level of miR-3163. Patients $>50(n=31)$, patients $<=50(n=31)$, age unknown for $(n=18)$ cases. ( $p$-value= 0.3805). 


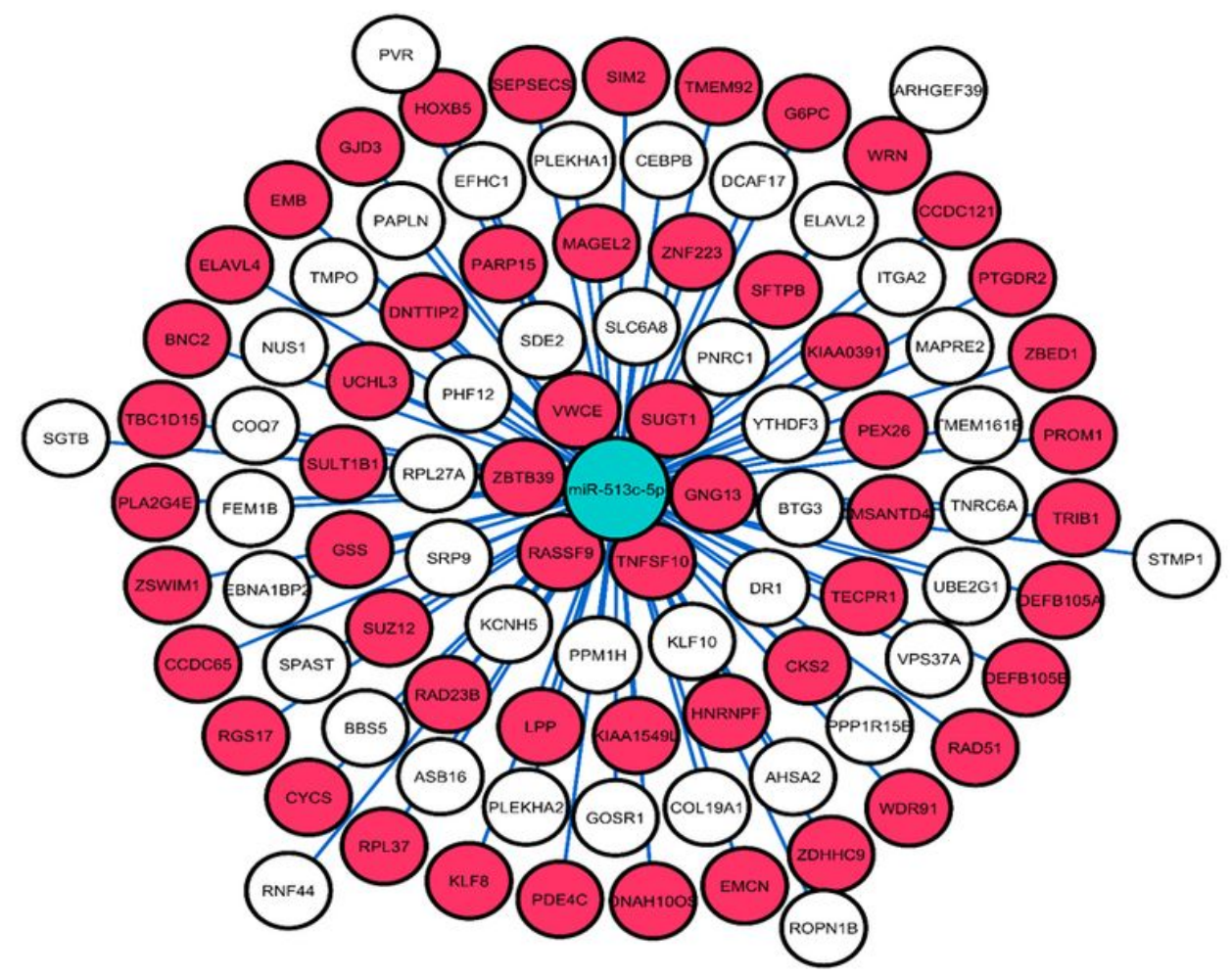

Figure 3

The interaction between miR-513c-5p and its target genes.

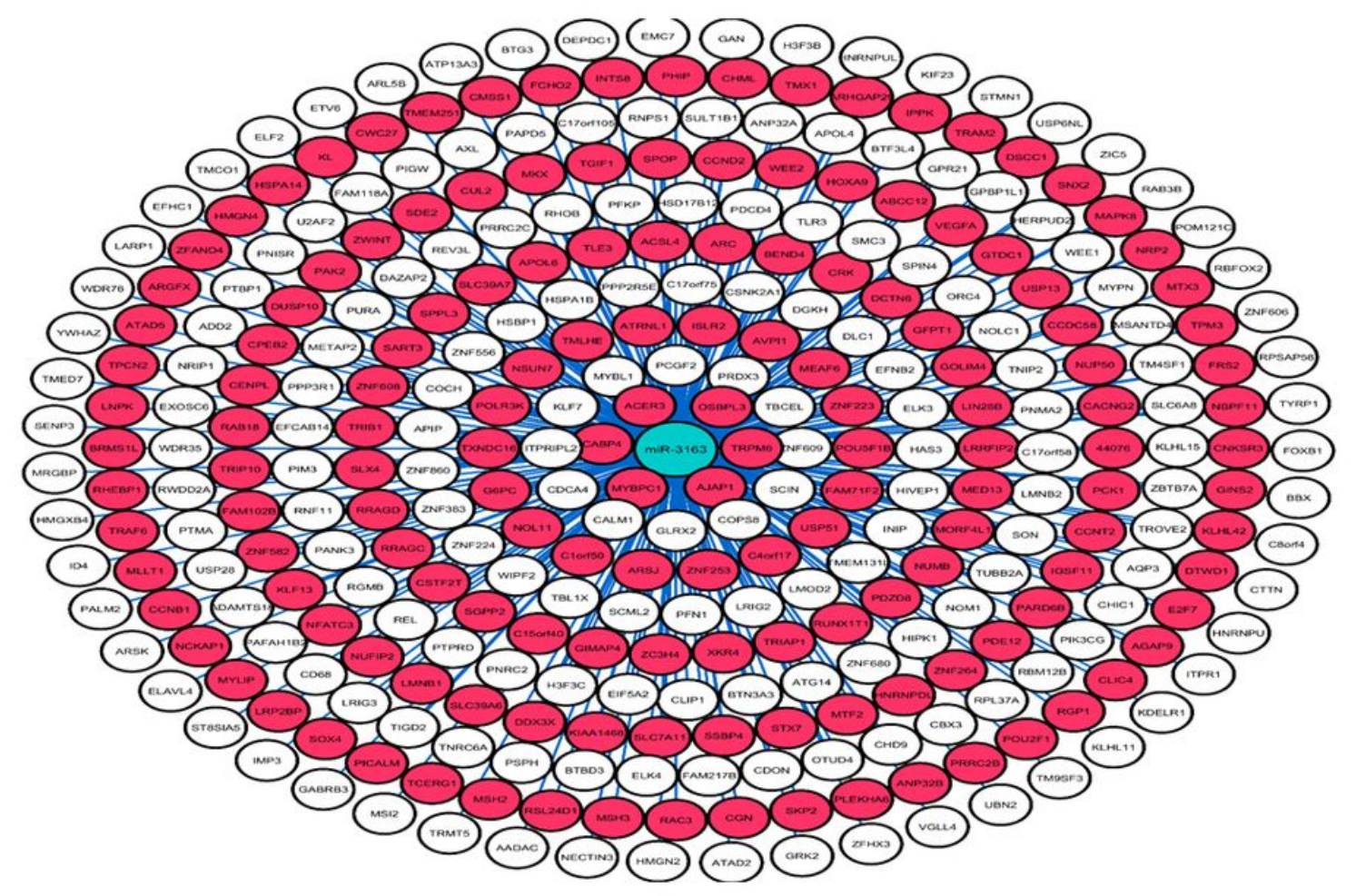

Figure 4 
The interaction between miR-3163 and its target genes.

Page 16/16 